\title{
PPAR $\gamma$ 1-Induced Caveolin-1 Enhances Cholesterol Efflux and Attenuates Atherosclerosis in Apolipoprotein E-Deficient Mice
}

\author{
Qin Hu ${ }^{a}$ Xian-jun Zhang ${ }^{b}$ Chun-xi Liu ${ }^{a}$ Xu-ping Wang ${ }^{a}$ Yun Zhang ${ }^{a}$ \\ ${ }^{a}$ Key Laboratory of Cardiovascular Remodeling and Function Research, Chinese Ministry of Education and \\ Chinese Ministry of Health, and ${ }^{\mathrm{b}}$ Department of Dermatology, Shandong University Qilu Hospital, Jinan, China
}

\section{Key Words}

Caveolin-1 $\cdot$ PPAR $y \cdot$ Macrophages $\cdot$ Atherosclerosis

\begin{abstract}
Objective: Caveolin-1 (Cav-1) may positively or negatively influence the development of atherosclerosis, depending on the cell type and the metabolic pathways regulated by this protein. We investigate the effects of Cav-1 on cholesterol efflux in RAW264.7 infected with AdPPAR 1 and whether Cav-1 could attenuate established atherosclerotic lesions in PPAR 1-treated apoE-deficient mice. Methods and Results: Compared with AdGFP control, PPAR 1 and Cav-1 were constitutively overexpressed in AdPPAR $\gamma 1$-infected RAW264.7 cells, which stimulated cholesterol efflux to apolipoprotein A-I. Using a small interfering RNA approach (Cav-1-siRNA) we achieved an efficient and specific knockdown of caveolin-1 expression (80\%), which resulted in a remarkable reduction of cholesterol efflux in RAW264.7 cells . Moreover, PPARy1treated Cav-1-siRNA RAW264.7 cells showed more ability to stimulate cholesterol efflux than Cav-1-siRNA RAW264.7 cells, but far less than control-siRNA RAW264.7 cells and PPARy1-treated RAW264.7 cells. In addition, 40-week-old apoE-deficient mice fed a Western-type diet and infected for 4 weeks with AdPPAR 1 showed induced Cav-1 expression in aortic vascular endothelial cells, smooth muscle cells and
\end{abstract}

macrophages, as well as attenuated established atherosclerotic lesions. Conclusions: PPAR 11 gene therapy could induce Cav-1 expression and enhance cholesterol efflux and attenuate atherosclerosis in apoE-deficient mice.

Copyright $\odot 2009$ S. Karger AG, Basel

\section{Introduction}

Caveolae are the primary plasmalemmal vesicle type found in normal vascular cells and are implicated in several basic processes, including endocytosis, potocytosis, cellular signaling and cholesterol homeostasis $[1,2]$. Caveolae are 50 - to 100 -nm cell-surface plasma-membrane invaginations highly enriched in cholesterol and sphingolipids and characterized by the protein marker caveolin-1 (Cav-1). Cav-1 is a 178-amino-acid integral plasma membrane protein that drives caveolae formation through oligomerization (with itself and with Cav-2) and by interacting with cholesterol [3]. Cav-1 is highly expressed in terminally differentiated cells $[4,5]$.

However, much controversy surrounds whether the vascular cells that make up the atherosclerotic plaque

Qin Hu, Xian-jun Zhang and Chun-xi Liu contributed equally to this study.

\section{KARGER}

Fax +41613061234 E-Mail karger@karger.ch www.karger.com (c) 2009 S. Karger AG, Basel

$1018-1172 / 10 / 0471-0069 \$ 26.00 / 0$

Accessible online at:

www.karger.com/jvr
Dr. Yun Zhang

Shandong University Qilu Hospital

No. 107, Wen Hua Xi Road

Jinan, Shandong, 250012 (PR China)

Tel./Fax +86 5318616 9356, E-Mail zhangyun@sdu.edu.cn 
even express caveolins or have caveolae-type organelles. Among these cells, macrophages, endothelial and smooth muscle cells all play key roles in the development of atherosclerosis [6]. Cav-1 is considered a negative regulator of endothelial nitric oxide synthase and plays an important role in influencing various aspects of cardiovascular functions [7]. Previous study has shown that atherosclerotic lesion area is markedly reduced in apoE ${ }^{-/-} \mathrm{Cav}_{-1} \mathrm{I}^{-/}$ double knockout mice, which indicates that a lack of Cav1 inhibits atherogenesis [7]. However, neointima formation is exacerbated in the carotid arteries of Cav-1 $1^{-/-}$mice after surgical ligation [8]. Thus, endothelial cell Cav-1 may have a pro-atherogenic role and smooth muscle cell Cav-1 the opposite role. So Cav-1 may positively or negatively influence the development of vascular disease, depending on the cell type and the metabolic pathways regulated by this protein [8]. But the role of macrophage Cav1 on atherosclerosis remains unclear.

Previous studies have suggested that Cav-1 expression is regulated by peroxisome proliferator-activated receptor $\gamma$ (PPAR $\gamma$ ) in cell types such as human adenocarcinoma and hepatic cells $[9,10]$. PPAR $\gamma$ is an important transcription factor and is involved in atherosclerosis progression [11]. Recently, we have demonstrated that PPAR $\gamma 1$ gene transfer exerts beneficial effects in attenuating atherosclerosis progression and stabilizes vulnerable plaques [12]. To determine the relationship between Cav-1 and PPAR $\gamma 1$ in vascular cell and further identify a role of Cav-1 on atherosclerosis, we chose to use small interfering RNA (siRNA) to transiently and specifically knockdown expression of Cav-1 and adenovirus-mediated PPAR $\gamma 1$ gene overexpression in RAW264.7 cells. We investigated whether PPAR $\gamma 1$-induced Cav-1 could attenuate established atherosclerotic lesions in $\mathrm{apoE}^{-/-}$ mice.

\section{Materials and Methods}

Synthesis and Transfection of siRNA

siRNA sequences targeting mice Cav-1 gene (AACGCGCACACCAAGGAGATT) were synthesized (Dharmacon Inc., Lafayette, Colo., USA). The sequence (AACCAGAAGGGACACACAGTT) targeting the human Cav-1 gene with no apparent effects in mice cells was used as a negative control (Ctr-siRNA). For transfection, cells were plated on 6-well plates. Transfections were performed with TransIT-TKO reagent (Mirus Corp., Madison, Wisc., USA), as directed by the manufacturer. Each well received $10 \mathrm{nM}$ siRNA in a volume of $1 \mathrm{ml}$, in triplicate.

Recombinant Adenovirus

We constructed recombinant adenovirus containing the mouse PPAR $\gamma 1$ cDNA (Ad/mPPAR $\gamma 1)$ as described by He et al.
[13]. The plasmid of PCMX-mPPAR $\gamma 1$ and the AdEasy vector were provided by Dr. Ronald M. Evans (Salk Institute, San Diego, Calif., USA) and Dr. Tong-Chun He (Howard Hughes Medical Institute, Chevy Chase, Md., USA), respectively.

\section{Cells and Cell Culture}

A murine macrophage cell line, RAW264.7, from the American Type Culture Collection (Manassas, Va., USA) was used for all experiments. Cells were maintained in RPMI 1640 (Invitrogen, Carlsbad, Calif., USA) supplemented with $5 \mathrm{mM}$ L-glutamine, $100 \mathrm{units} / \mathrm{ml}$ penicillin and streptomycin, and $10 \%$ fetal calf serum, at $37^{\circ} \mathrm{C}$ and $5 \% \mathrm{CO}_{2}$. For experiments, cells were cultured in the same media, except $0.2 \%$ fetal calf serum was used. Adenovirus was dissolved in phosphate-buffered saline(PBS). RAW264.7 cells were randomly divided into 5 groups: AdPPAR $\gamma 1$ group and AdGFP group (both multiplicity of infection = 5), Cav-1-siRNA group, PPAR 1 1-treated Cav-1-siRNA group and Ctr-siRNA group. Fresh medium was added $5 \mathrm{~h}$ after transfection, and experiments were conducted $48 \mathrm{~h}$ after transfection.

\section{Immunocytochemistry}

Cells treated with AdGFP or AdPPAR $\gamma 1$ were harvested and fixed in ice acetone for $15 \mathrm{~min}$ and stored at $-20^{\circ} \mathrm{C}$ until use. Fixed cells were incubated with $5 \%$ bovine serum albumin (BSA; SigmaAldrich, St. Louis, Mo., USA) for $20 \mathrm{~min}$, then treated with a mouse monoclonal anti-mouse PPAR $\gamma$ antibody (1:50) or rabbit polyclonal anti-human Cav-1 antibody (1:100; Santa Cruz Biotechnology, Santa Cruz, Calif., USA) overnight at $4^{\circ} \mathrm{C}$ and incubated with the secondary biotinylated anti-mouse and anti-rabbit antibody for $30 \mathrm{~min}$ after a washing in PBS $(3 \times 5 \mathrm{~min})$. After a further washing in PBS, streptavidin conjugate was applied for 30 min. Then cells were washed again with PBS and counter-stained by $3,3^{\prime}$-diaminobenzidine for $5-10 \mathrm{~min}$. In negative controls, the same method was used except for omitting incubation with the primary antibody.

\section{Reverse-Transcriptase PCR}

Total RNA from RAW264.7 cells of different intervention groups and control group was isolated by the Rneasy method (Trizol reagent) according to the manufacturer's protocol. Then, the amount and quality of RNA were determined before analysis. Contaminating DNA was degraded by use of 1 unit DNase-I (Invitrogen, Karlsruhe, Germany) per microgram of total RNA. mRNA levels of PPAR $\gamma 1$ and Cav-1 were determined by RT-PCR. Briefly, $1 \mu \mathrm{g}$ of total RNA was used to generate first-strand cDNA with use of an oligo dT oligodeoxynucleotide primer $\left(\mathrm{T}_{12-18}\right)$ following the description of M-MLV Reverse Transcriptase (Promega, Madison, Wisc., USA). The primers were made by Invitrogen Life Technologies. $\beta$-actin (NM007393): 5'-ATGGATGACGATATCGCT-3', 5' - ATGAGGTAGTCTGTCAGGT-3' (569 bp). PPAR $\gamma 1$ (U01841): forward 5'-GTCGACATGGTTGACACAGAGATGC-3', reverse 5'-TCTAGACTAATACAAGTCCTTGTA-3' (1,440 bp). Caveolin-1 (NM007616): forward 5'-CAGCATGTCTGGGGGTAAAT-3', reverse 5'-TGCTTCTCATTCACCTCGTCT-3' (341 bp). Equal amounts of cDNA were used in triplicate and amplified with use of the Premix Ex Taq ${ }^{\mathrm{TM}}$ kit (Takara Bio Inc., Otsu, Japan) according to the manufacturer's instructions. Reactions were prepared with 1.5 units of Taq DNA polymerase, $10 \mathrm{mM}$ Tris/ $\mathrm{HCl}, \mathrm{pH} 9.0$ at room temperature, $50 \mathrm{mM} \mathrm{KCl,} 1.5 \mathrm{mM}$ $\mathrm{MgCl}_{2}, 0.2 \mathrm{mM}$ dNTPs, $0.4 \mu \mathrm{M}$ sense and antisense primers, and 
overlaid with $40 \mu \mathrm{l}$ of mineral oil. Amplification was undertaken by denaturation at $95^{\circ} \mathrm{C}$ for $30 \mathrm{~s}$, annealing at $57^{\circ} \mathrm{C}$ for $30 \mathrm{~s}$ and extension at $72^{\circ} \mathrm{C}$ for $1.5 \mathrm{~min}$ with a final $7 \mathrm{~min}$ extension time at $72^{\circ} \mathrm{C}$. RT-PCR products were analysed in a $2 \%$ agarose gel containing ethidium bromide. The quantification value of the bands in the gel was designated the 'optical density' (pixels). Amplification efficiencies were validated and normalized against $\beta$-actin.

\section{Immunoblotting Experiments}

For Western blot analysis, about $10^{7}$ cells were washed in PBS and solubilized buffer $(50 \mathrm{mmol} / \mathrm{l}$ Tris- $\mathrm{HCl}, \mathrm{pH} 7.4,125 \mathrm{mmol} / \mathrm{l}$ $\mathrm{NaCl}, 0.1 \%$ NP-40, $5 \mathrm{mmol} / \mathrm{l} \mathrm{NaF}, 1 \mathrm{mmol} / \mathrm{l} \mathrm{PMSF}, 1 \mathrm{ng} / \mathrm{ml} \mathrm{leu}-$ peptin, $10 \mathrm{ng} / \mathrm{ml}$ soybean trypsin inhibitor, $1 \mathrm{ng} / \mathrm{ml}$ aprotinin, 10 $\mathrm{ng} / \mathrm{ml} \mathrm{N}$-tosyl-L-phenylalanyl chloromethyl ketone) for $60 \mathrm{~min}$ on ice. Lysates were centrifuged at 2,500 $\mathrm{g}$ for $5 \mathrm{~min}$. The protein concentrations in RAW264.7 cells were measured by the bicinchoninic acid protein assay, with BSA used as the protein standard. $20 \mu \mathrm{g}$ of protein extracts were mixed with SDS-PAGE sample buffer, boiled for $5 \mathrm{~min}$, electrophoresed on $10 \%$ SDS-polyacrylamide gel, then transferred to PVDF membranes (Millipore, Billerica, Mass., USA). After subsequent washing in $25 \mathrm{mM}$ Trisbuffered saline with $0.05 \%$ Tween-20 (TTBS), the unspecific binding sites were saturated by incubation with $10 \%$ non-fat dry milk in TTBS for $1 \mathrm{~h}$ at room temperature. The membranes were incubated overnight at $4^{\circ} \mathrm{C}$ with primary antibody against PPAR $\gamma$ or Cav-1 (both 1:2,000). The secondary anti-mouse and anti-rabbit antibodies (1:100) were diluted in $2.5 \%$ non-fat dry milk in TTBS and incubated for $1 \mathrm{~h}$ at room temperature; chemiluminescent signal was developed by use of ECL Advance (GE Healthcare, Amersham, UK). Anti-actin monoclonal antibody $(1 \mu \mathrm{g} / \mathrm{ml}$ dilution; Sigma-Aldrich) was hybridized to membranes to serve as a measure of loading control. Controls involved omitting the primary antibody. Densitometric analysis involved use of NIH Image 1.62 software. Ratios for PPAR $\gamma / \beta$-actin and Cav- $1 / \beta$-actin protein were calculated for each sample and expressed as the mean \pm SEM. The experiment was performed in triplicate and repeated 3 times.

\section{Cholesterol Efflux Assay}

Based on slight modification of Ghering AB's assay for cholesterol efflux [14], RAW264.7 cells on 24-well plates were infected with control, or Cav-1 siRNAs or AdPPAR $\gamma 1$ as described above. At $48 \mathrm{~h}$ after transfection, the cells were labeled for $24 \mathrm{~h}$ with 0.5 $\mu \mathrm{Ci} / \mathrm{ml} 1,2-[3 \mathrm{H}]$ cholesterol (GE Healthcare). RAW264.7 cells from different intervention groups and control group were then washed 3 times with PBS and incubated for $2 \mathrm{~h}$ at $37^{\circ} \mathrm{C}$ with RPMI $1640,0.2 \%$ fatty acid free BSA. The medium was replaced with fresh RPMI 1640/BSA with or without pure lipid-free human apoA-I $(10 \mu \mathrm{g} / \mathrm{ml})$ and incubated at $37^{\circ} \mathrm{C}$ for $6 \mathrm{~h}$. The media were then collected and analyzed by liquid scintillation counting. Cells were dissolved in $0.2 \mathrm{~N} \mathrm{NaOH}$ and the cellular radioactivity was determined. The efflux is expressed as a percent of the total $[3 \mathrm{H}]$ cholesterol radioactivity present in the cells + the efflux medium.

\section{Animal Protocol}

Male apoE-deficient mice on a C57Bl/6 background (20 weeks of age) fed a regular chow were purchased from the department of medical science at Beijing University, then bred and maintained in the center for animal experiments at Shandong Univer- sity. The mice were kept in separate cages in a 12-hour light/dark cycle, allowed to acclimatize for 1 week before the study started, then fed a Western-type diet containing $21 \%$ fat (wt/vol), and $0.15 \%$ cholesterol (wt/wt) until sacrifice. New batches of food were prepared weekly and stored at $4^{\circ} \mathrm{C}$. All animals had free access to water. AdPPAR $\gamma 1\left(5 \times 10^{8} \mathrm{pfu}\right)$ or $\operatorname{AdGFP}\left(5 \times 10^{8} \mathrm{pfu}\right.$; vehicle control) diluted to a total volume of $200 \mu \mathrm{l}$ was injected into the tail vein of each group of mice (at 40 weeks of age, $n=20$ ). We sacrificed all animals 4 weeks later. The investigation conformed with the institutional animal care and use committee protocol at Shandong University and were consistent with the Guide for the Care and Use of Laboratory Animals published by the US National Institutes of Health.

\section{Lipoprotein Profiles}

Blood samples (approx. $0.4 \mathrm{ml} /$ mouse) were taken from the vena jugular of each mouse before the treatments and before sacrifice for assays of lipids and lipoproteins. Blood samples were obtained from each animal in a fasting state and drawn into EDTA-coated microcapillary tubes. Plasma was isolated from whole blood and glucose levels were determined. Serum levels of total cholesterol, triglyceride, low-density lipoprotein and highdensity lipoprotein were measured by enzymatic assays using an automated bichromatic analyzer (Hitachi 7170A, Tokyo, Japan).

\section{Tissue Preparation}

After mice were anesthetized by intraperitoneal injection of pentobarbital $(30 \mathrm{mg} / \mathrm{kg})$, the chest was opened and the heart was exposed. The heart was perfused with cold PBS for 3 min via a catheter in the left ventricle from its apex and a free efflux of blood from the heart was allowed by cutting the right atrium, followed by perfusion fixation with phosphate-buffered $4 \%$ paraformaldehyde, $\mathrm{pH}$ 7.0-7.4, for $7 \mathrm{~min}$. The perfusion pressure was kept constant at $100 \mathrm{~mm} \mathrm{Hg}$. The heart containing the aortic sinus and aortic arch was rapidly harvested and fixed overnight at room temperature in phosphate-buffered $4 \%$ paraformaldehyde, $\mathrm{pH}$ 7.0-7.4. The adventitial side of the thoracic aorta was carefully dissected free from fat. The stubs of the intercostal arteries were trimmed close to the aorta. Under a dissection microscope, the remaining aortic arch and descending aorta were fixed in $4 \%$ paraformaldehyde for measurement of the surface area covered by lipid-staining lesions. The frozen cross-sections of the aortic sinus embedded in Optimal Cutting Temperature compound (Sakura Finetek, Torrance, Calif., USA) were mounted on slides for histology and immunohistochemistry. The liver, the remaining aortic arch and the descending aorta were separated and quickly fixed or frozen. mRNA levels of PPAR 1 1, Cav-1, liver X receptor $\alpha(\mathrm{LXR} \alpha)$ and ATP-binding cassette transporter A1 (ABCA1) from the liver of $a \mathrm{poE}^{-/-}$mice were determined by quantitative real-time RT-PCR. The primers were also made by Invitrogen Life Technologies. $\beta$-actin: $5^{\prime}$-CACTGTGCCCATCTACGA-3', 5'-GTAGTCTGTCAGGTCCCG-3'. PPAR $\gamma 1$ : forward 5'-GCCCAGGCTTGCTGAACG-3', reverse 5'-GGAGCACCTTGGCGAACA-3'. Caveolin-1: forward 5'-CAGCATGTCTGGGGGTAAAT-3', reverse 5'-TGCTTCTCATTCACCTCGTCT-3'. ABCA1: forward 5'-CCAGTAACTACAGTGGCGGCAA-3', reverse 5'-TCTTCTATGTGGAGTCGCTTTT-3'. LXR $\alpha$ : forward 5'-TGAAGCGGCAAGAAGAGGAACA-3', reverse 5'GATGGCAATGAGCAGAGCAAAC-3'. Equal amounts of CDNA were used in triplicate and amplified with use of the 
SYBR ${ }^{\circledR}$ Premix Ex Taq kit (Takara Bio Inc.) according to the manufacturer's instructions. Reactions were prepared with $10 \mu \mathrm{lSYBR}$ Premix Ex Taq, $0.8 \mu$ l forward primer $(5 \mu \mathrm{M}), 0.8 \mu$ l reverse primer $(5 \mu \mathrm{M})$, and $2 \mu \mathrm{lcDNA}$, in a final volume of $20 \mu \mathrm{l}$. The reactions were carried out on the LightCycler 4.0 (Roche, USA) for 10s at $95^{\circ} \mathrm{C}$, followed by 40 cycles with denaturation at $95^{\circ} \mathrm{C}$ for $15 \mathrm{~s}$, annealing at $52-55^{\circ} \mathrm{C}$ for $5 \mathrm{~s}$, and extension at $72^{\circ} \mathrm{C}$ for $10 \mathrm{~s}$. Amplification efficiencies were validated and normalized against $\beta$-actin, and the products were calculated by the standard curve method for quantitation according to LightCycler 4.0. The qRTPCR products were analyzed by electrophoresis on a $2 \%$ Tris-acetate-EDTA agarose gel. Immunoblotting was used to determine the levels of Cav-1 protein, similar to cellular protein level assay.

\section{Histology and Immunohistochemistry}

Transverse $7-\mu \mathrm{m}$ cross-sections of the aortic root were prepared, serially mounted, and routinely stained with Oil Red O, hematoxylin and eosin, and Movat's pentachrome staining for differentiation of muscle, various connective tissue components, mucinous secretions and intra-cytoplasmic structures. The remaining sections were used for immunohistochemical analysis. Frozen serial sections were treated with $0.3 \% \mathrm{H}_{2} \mathrm{O}_{2}$ in PBS to block endogenous peroxidase activity, followed by blocking in $5 \%$ BSA. Sections were incubated with either a mouse monoclonal antibody against mouse PPAR $y$ at 1:50 dilution (Santa Cruz Biotechnology), purified rabbit polyclonal antibody against human Cav-1 at 1:50 dilution (Santa Cruz Biotechnology) or a purified rat monoclonal antibody against mouse macrophages (MOMA-2; Millipore) at 1:25 dilution. For $\alpha$-smooth muscle actin studies, a kit (Sigma-Aldrich) was used. Peroxidase-labeled anti-mouse, anti-rabbit or anti-rat antibodies, at 1:50 dilution, were used as second antibodies. The activity of peroxidase was revealed with diaminobenzidine (Merck), yielding a yellow-brown deposit. The sections were then counterstained with hematoxylin. Negative controls included sections with the first antibodies omitted.

\section{Data and Statistical Analysis}

All experiments in vitro were performed at least 3 times. All data are means \pm SEM, unless otherwise specified. Differences between groups were determined by 2 -way ANOVA and a multiple comparison test. A p $<0.05$ was considered significant. All images were captured by use of an Olympus microscope equipped with a video camera and analyzed by NIH Image 1.62 software.

\section{Results}

\section{PPAR $\gamma 1$ Gene Transfer Induces Caveolin-1 Expression} in Macrophages

The protein Cav-1 is the major coat protein for the organelle caveolae. To determine whether PPAR $\gamma 1$ gene transfer induced the expression of Cav-1 in macrophages, RAW264.7 cells were incubated with AdPPAR $\gamma 1$. Compared with vector control cells (AdGFP), these cells constitutively overexpressed PPAR $\gamma 1$, and immunocytochemistry showed Cav-1 localized in the membrane compartment (fig. 1a). Compared with the AdGFP group,
AdPPAR $\gamma 1$-treated cells showed significantly increased Cav-1 expression in the cellular membrane (fig. 1a, b). qRT-PCR also demonstrated that AdPPAR $\gamma 1$-treated cells showed significantly increased Cav-1 mRNA levels (fig. 1c). Thus, PPAR $\gamma 1$ overexpression induced increased Cav-1 mRNA and protein levels in RAW macrophages.

\section{PPAR $\gamma 1$ Gene Transfer Induces Caveolin-1 Expression in Macrophages, Endothelial and Smooth Muscle Cells, which Make up Atheromatous Plaques}

Many tissues, such as the liver and the aorta, normally express PPAR $\gamma$ and Cav-1 at a lower level. 28 days after adenovirus injection, PPAR $\gamma$ immunoreactivity in the liver and the aorta was markedly upregulated in AdPPAR $\gamma 1-$ infected mice but not AdGFP-infected mice (online suppl. fig. 1, 2; www.karger.com/doi/10.1159/000235927). We also found Cav-1 levels were markedly increased in atheromatous plaques of AdPPAR $\gamma 1$-infected mice as compared with AdGFP-infected mice, as assessed by immunohistochemistry ( $89 \pm 2 \%$ vs. $47 \pm 1 \%, \mathrm{p}<0.05$; fig. $2 \mathrm{a}$, b). Moreover, upregulated Cav-1 was chiefly expressed in endothelial cells, smooth muscle cells and macrophages, which make up atheromatous plaques. This phenomenon was also confirmed by immunoblotting analysis (AdPPAR $\gamma$ vs. AdGFP: $2.45 \pm 0.13$ vs. $0.21 \pm 0.05$, respectively, $\mathrm{p}<0.05$; fig. $2 \mathrm{c}$ ). In addition, qRT-PCR analysis revealed that PPAR $\gamma 1$ overexpression markedly increased Cav-1 mRNA expression in the liver of AdPPAR $\gamma 1$-infected mice compared with AdGFP-infected mice $(0.58 \pm 0.02$ vs. $0.21 \pm 0.05, \mathrm{p}<0.05$; fig. 3$)$.

Fig. 1. PPAR $\gamma 1$ gene transfer upregulated Cav-1 expression in RAW264.7 cells. a Fixed cells transfected with AdGFP and AdPPAR $\gamma$ were stained with PPAR $\gamma$ antibody (upper panels) or Cav-1 antibody (lower panels). PPAR $\gamma 1$ was chiefly localized in the cytoplasm and nucleus. Scale bar $=100 \mu \mathrm{m}$. b Immunoblotting results of PPAR $\gamma$ and Cav-1 protein expression in RAW264.7 cells treated with AdGFP and AdPPAR $\gamma 1$. Upper panel: representative results of immunoblotting. Lower panel: ratio of the band intensity of PPAR $\gamma$ and Cav-1 protein with AdPPAR $\gamma 1$ treatment to AdGFP treatment after normalizing intensities to that of $\alpha$-actin. c RT-PCR results of PPAR $\gamma 1$ and Cav- 1 mRNA expression. Upper panel: PCR products were size separated on agarose gels (1.5\%). The specific 1,440-, 341- and 596-bp DNA fragments are for PPAR $\gamma 1, \mathrm{Cav}-1$ and $\beta$-actin, respectively. Lower panel: ratio of the band intensity of PPAR $\gamma 1$ and Cav-1 mRNA with AdPPAR $\gamma 1$ treatment to AdGFP treatment after normalizing intensities to that of $\beta$-actin. Error bars $=$ SEM. ${ }^{*} p<0.05$ vs. AdGFP group. 


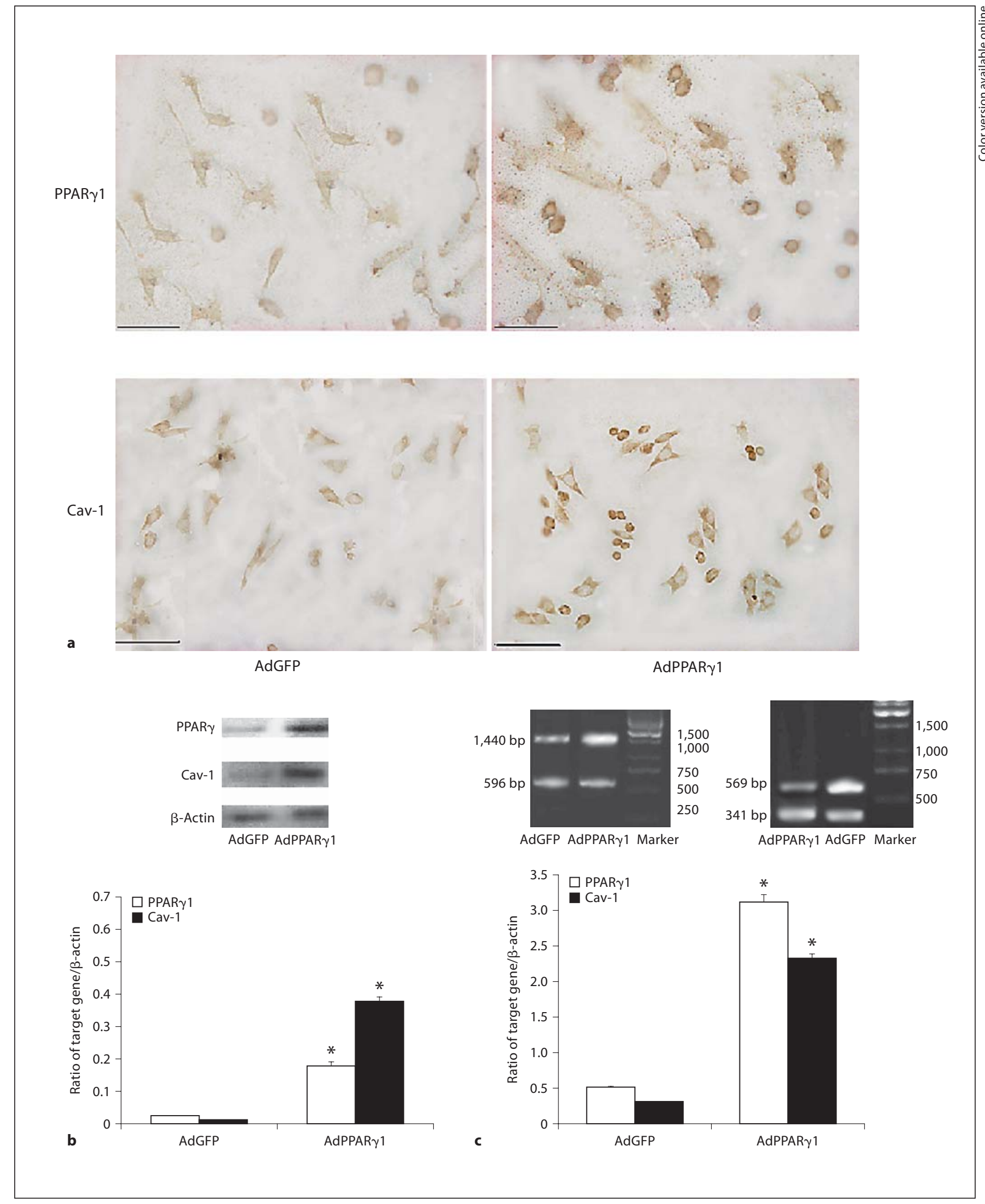




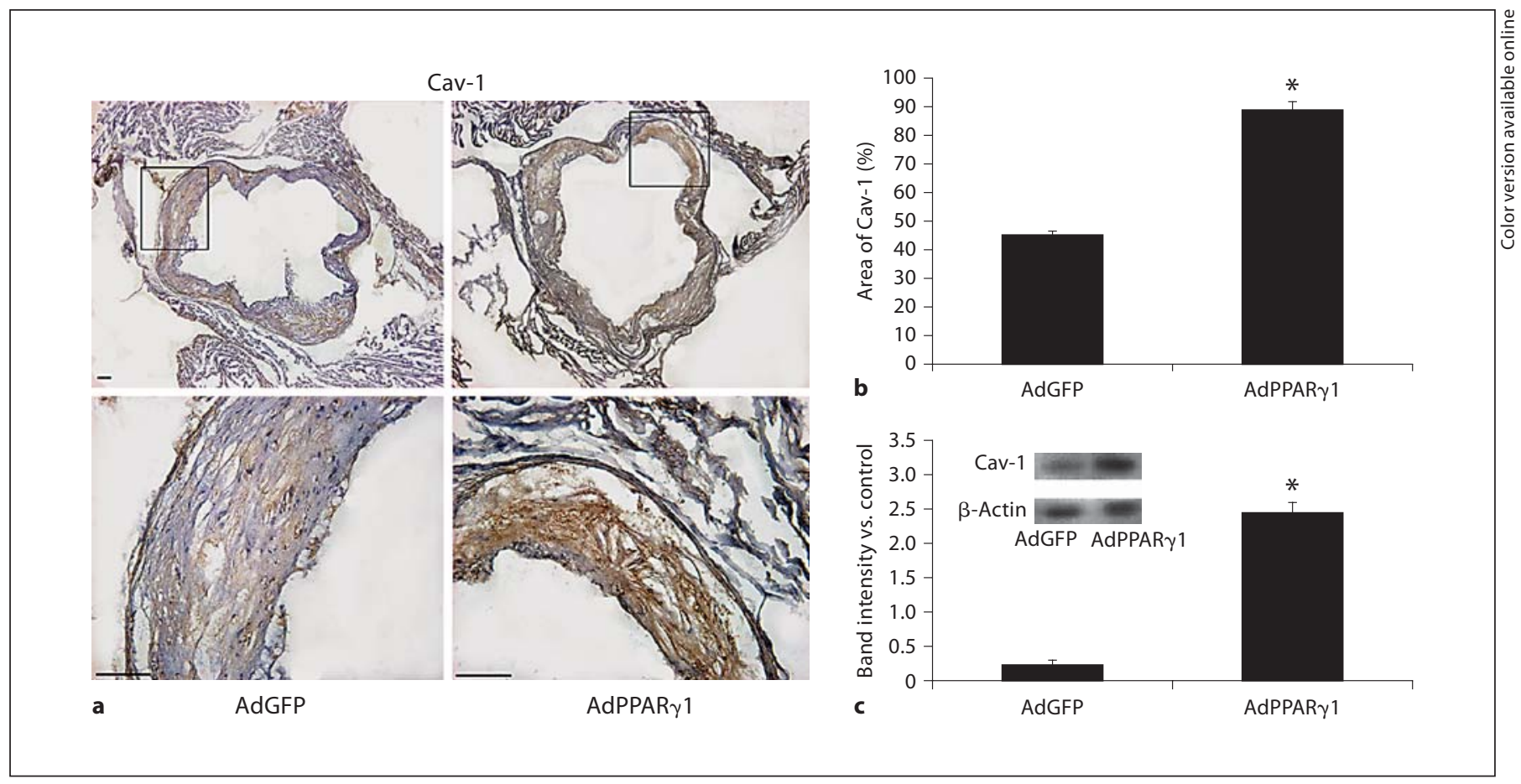

Fig. 2. a PPAR $\gamma 1$ gene transfer induces Cav-1 expression in atheromatous plaques. Sections of representative lesions in the aortic roots of AdPPAR $\gamma 1$ - or AdGFP-transfected mice were stained with Cav-1 antibody. Lower panels are enlargements of the upper panels $(\times 20)$ and show the Cav-1(+) lesion in the aortic roots. Scale bars $=100 \mu \mathrm{m}$. b Percentage of area of Cav-1 on immu- nohistochemistry. $\mathrm{n}=15$. Error bars $=$ SEM. ${ }^{*} \mathrm{p}<0.05$ vs. the AdGFP group. c Immunoblotting analysis of PPAR $\gamma$ and Cav-1 protein expression in apoE deficient-mice treated with AdGFP and AdPPAR 1 . Graph shows ratio of the band intensity of PPAR $\gamma$ and Cav-1 protein with AdPPAR $\gamma 1$ treatment to AdGFP treatment after normalizing intensities to that of $\beta$-actin.



Fig. 3. PPAR $\gamma 1$ gene therapy increased $\operatorname{PPAR} \gamma 1, \mathrm{LXR} \alpha, \mathrm{ABCA} 1$ and Cav-1 expression in the liver extracts from apoE-deficient mice. Data are expressed as the ratio of $\mathrm{mRNA}$ to the corresponding $\beta$-actin mRNA. $n=15$. Error bars $=$ SEM. ${ }^{*} \mathrm{p}<0.05$ vs. the AdGFP group.
Fig. 4. PPAR $\gamma 1$ gene therapy inhibits progression of established atherosclerotic lesions in apoE-deficient mice. Photomicrographs of atherosclerotic lesions stained with Oil red $\mathrm{O}$ in the aorta (a) and aortic root (b), and lesions stained with hematoxylin and eo$\sin$ (c). Scale bar $=100 \mu \mathrm{m}$. Microscopic cross-sections of the proximal aortic root were stained with hematoxylin and eosin and quantitated by morphometry. d Quantitative analysis of lesion areas $\left(\mathrm{mm}^{2}\right)$ in the aortic root of AdGFP mice $(\mathrm{n}=15)$ and AdPPAR $\gamma 1$ mice $(n=15)$. Means $\pm S D$ are shown. Each symbol represents the average lesion area from 5 sections of a single mouse. Horizontal bars indicate the mean of the group, and vertical bars indicate the SD. AdPPAR $\gamma 1$-infected mice had a greatly decreased macrophage area in plaque, with significantly increased smooth muscle cell area. e, $\mathbf{f}$ Lesions in the aortic roots of apoEdeficient mice stained with anti-murine macrophage antibody (MOMA-2) or anti-human $\alpha$-smooth muscle actin antibody. g Error bars $=$ SEM. ${ }^{*} \mathrm{p}<0.05$ vs. the AdGFP group. $\mathrm{n}=15 . \mathbf{h}$ The matrical component stained dark green-yellow to blue with Movat's pentachrome stain, which shows more dense collagen in the aortic roots of the AdPPAR $\gamma 1$-infected mice than in AdGFP-infected mice. In all images, lower panels are enlargements of the upper panels $(\times 20)$ showing the well-different antibody $(+)$ lesion in the aortic roots of AdGFP- or AdPPAR $\gamma 1$-infected mice. Scale bar $=100 \mu \mathrm{m}$. 


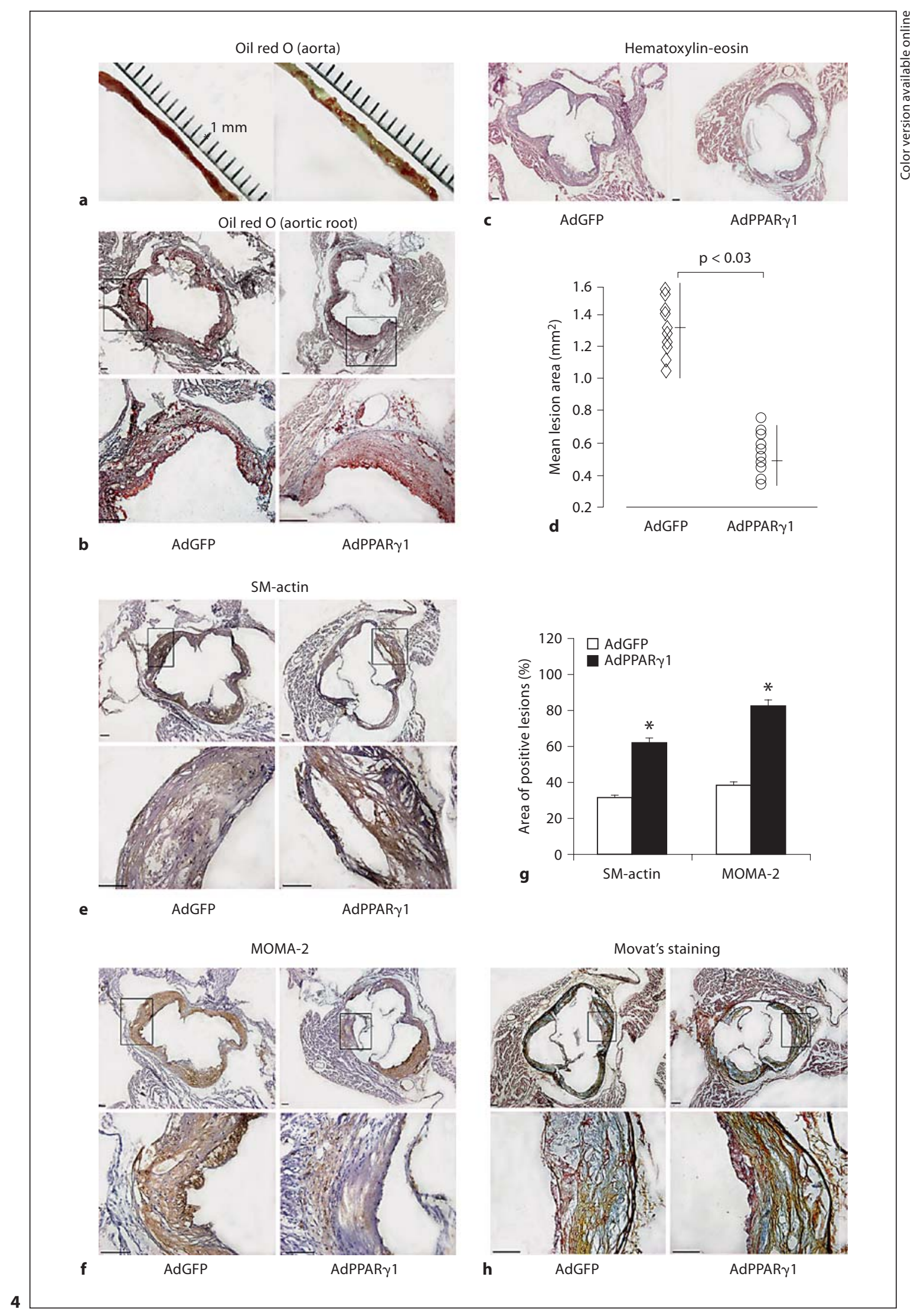

PPAR $\gamma 1-$ Induced Cav-1 Attenuates

J Vasc Res 2010;47:69-79 
Table 1. Plasma lipid profile

\begin{tabular}{lcl}
\hline Lipid and lipid profile & $\begin{array}{l}\text { AdGFP group } \\
(\mathrm{n}=20)\end{array}$ & $\begin{array}{l}\text { AdPPAR } \gamma 1 \text { group } \\
(\mathrm{n}=20)\end{array}$ \\
\hline Total cholesterol, $\mathrm{mmol} / \mathrm{l}$ & $20.4 \pm 0.7$ & $19.1 \pm 1.8$ \\
HDL cholesterol, $\mathrm{mmol} / \mathrm{l}$ & $1.5 \pm 0.2$ & $1.9 \pm 0.1^{*}$ \\
LDL cholesterol, $\mu \mathrm{mol} / \mathrm{l}$ & $5.9 \pm 0.5$ & $5.63 \pm 0.2$ \\
Triglycerides, $\mathrm{mmol} / \mathrm{l}$ & $3.68 \pm 0.23$ & $3.75 \pm 0.31$ \\
\hline
\end{tabular}

Data are means \pm SEM. ${ }^{*} \mathrm{p}<0.05$ vs. AdGFP group.

PPAR 71 -Induced Caveolin-1 Upregulation Attenuates Atherosclerosis

The above study demonstrated PPAR $\gamma 1$ gene transfer induced caveolin-1 upregulation in vivo and vitro. $\mathrm{Mi}$ croscopy revealed lesions in aortic roots in AdPPAR $\gamma 1$ infected mice mainly consisting of several layers of foam cells with some intracellular lipid accumulation but without a typical lipid core (fig. 4a, b). Typical atheromas with well-developed, lipid-rich cores and foam cell infiltration but not fibrous tissue proliferation were observed in some sections from the AdGFP-infected group (fig. 4a, b). The cross-sectional lesion areas of AdPPAR $\gamma 1$-infected mice were significantly smaller than those of the AdGFP-infected mice $\left(0.511 \pm 0.351\right.$ vs. $1.328 \pm 0.737 \mathrm{~mm}^{2}, \mathrm{p}<$ 0.05 ; fig. $4 c)$. En face staining surface atherosclerotic lesions of AdPPAR $\gamma 1$-infected mice were smaller in number than those of the AdGFP-infected group (24 vs. 38\%, $\mathrm{p}<0.05$; fig. 4d). Compared with the AdGFP-infected mice, AdPPAR $\gamma 1$-infected mice showed significantly downregulated lipid deposition in plaques (fig. 4b), and the macrophage area in plaque was greatly decreased (fig. 4e, g), whereas the smooth muscle cell area was significantly increased (fig. 4f, g). Similarly, PPAR $\gamma 1$ transfection also effectively preserved collagen and proteoglycan deposition in plaque (fig. 4h). Thus, PPAR $\gamma 1$-induced Cav-1 upregulation attenuates the progression of established atherosclerotic lesions in apoE-deficient mice.

\section{PPAR 1 1-Induced Caveolin-1 Attenuates Lipoprotein Metabolic Disorders}

To investigate possible mechanisms of the anti-atherogenic effects of PPAR $\gamma 1$-induced Cav-1 upregulation in apoE-deficient mice, lipoprotein levels were evaluated. Table 1 shows the plasma concentrations of lipid and lipoprotein profiles. High-density lipoprotein cholesterol level was increased, by $28.4 \%$, in AdPPAR $\gamma 1$-infected mice compared with AdGFP-infected mice, and there was no significant difference in plasma low-density lipoprotein, total cholesterol or triglyceride levels between the 2 groups. The mechanism of the beneficial effects of PPAR 1 1-induce Cav-1 upregulation on lipid profiles remains to be determined.

\section{Cav-1 Induced by PPAR $\gamma 1$ Enhanced Cholesterol Efflux to apoA-I}

Our demonstration of PPAR $\gamma 1$-induced Cav-1 upregulation raised the question of its enhancement of cholesterol efflux from foam cells. In the murine macrophage cell line RAW264.7, PPAR $\gamma 1$-induced Cav-1 upregulation enhanced cholesterol efflux (fig. 5). Cholesterol acceptors used were lipid-poor apoA-I. PPAR $\gamma 1$ is thought to promote cholesterol efflux through LXR-dependent and independent pathways [15]. To further test whether caveolin-1 is very important for cholesterol efflux, we utilized small interfering RNA for Cav-1. The results showed an efficient and specific knockdown of caveolin-1 expression (80\%), which resulted in the remarkable reduction of cholesterol efflux. In addition, PPAR $\gamma 1$-treated Cav-1siRNA RAW264.7 cells showed a greater ability to stimulate cholesterol efflux than Cav-1-siRNA RAW264.7 cells, but far less than Ctr-siRNA RAW264.7 cells and PPAR $\gamma 1-$ treated RAW264.7 cells ( $\mathrm{p}<0.05$; fig. 5).

\section{PPAR $\gamma 1$ Gene Transfer Upregulates Cholesterol \\ Efflux-Related Gene Expression in Liver of \\ apoE-Deficient Mice}

Cholesterol efflux enhancement may contribute to the beneficial effects of PPAR $\gamma 1$-induced Cav-1 upregulation on lipid profiles. In this study, we have demonstrated Cav-1 induced by PPAR $\gamma 1$ enhanced cholesterol efflux to apoA-I. Except for Cav-1 and PPAR $\gamma 1$, cholesterol efflux pathways involve a variety of factors, including the nuclear orphan receptors LXRs, as well as the proteins ABCA1 and SR-BI [16]. Previous study showed that PPAR $\gamma$ was not required for efflux from cholesterol-loaded macrophages via HDL or apoA-mediated pathways. To further assess the mechanism of enhanced cholesterol efflux from foam cells under PPAR $\gamma 1$ gene transfer, we quantified the corresponding mRNA levels of the cholesterol efflux-related molecules. A marked overexpression of ABCA1 and LXR $\alpha$ was discerned in AdPPAR $\gamma 1$-infected mice but not in AdGFP-infected mice (ABCA1: $0.35 \pm$ 0.07 vs. $0.12 \pm 0.05, p<0.05 ; \operatorname{LXR} \alpha: 0.29 \pm 0.03$ vs. 0.09 $\pm 0.02, \mathrm{p}<0.05$; fig. 3 ). 
Fig. 5. RAW264.7 cells treated with AdPPAR $\gamma 1$ and/or Cav-1siRNA were labeled with $[3 \mathrm{H}]$ cholesterol. Cholesterol efflux over $4 \mathrm{~h}$ to medium containing $0.2 \%$ albumin (no acceptor, NA), and albumin + lipid-free apoA-I at $10 \mu \mathrm{g} / \mathrm{ml}$ (apoA-I) was determined, as described in 'Material and Methods'. Error bars $=$ SEM $(n=6$ parallel specimens). ${ }^{a} \mathrm{p}<0.05$ vs. AdGFP group; ${ }^{\mathrm{b}} \mathrm{p}<0.05$ vs. Ctr-siRNA group; ${ }^{\mathrm{c}} \mathrm{p}<0.05$ vs. AdPPAR $\gamma 1$ group.

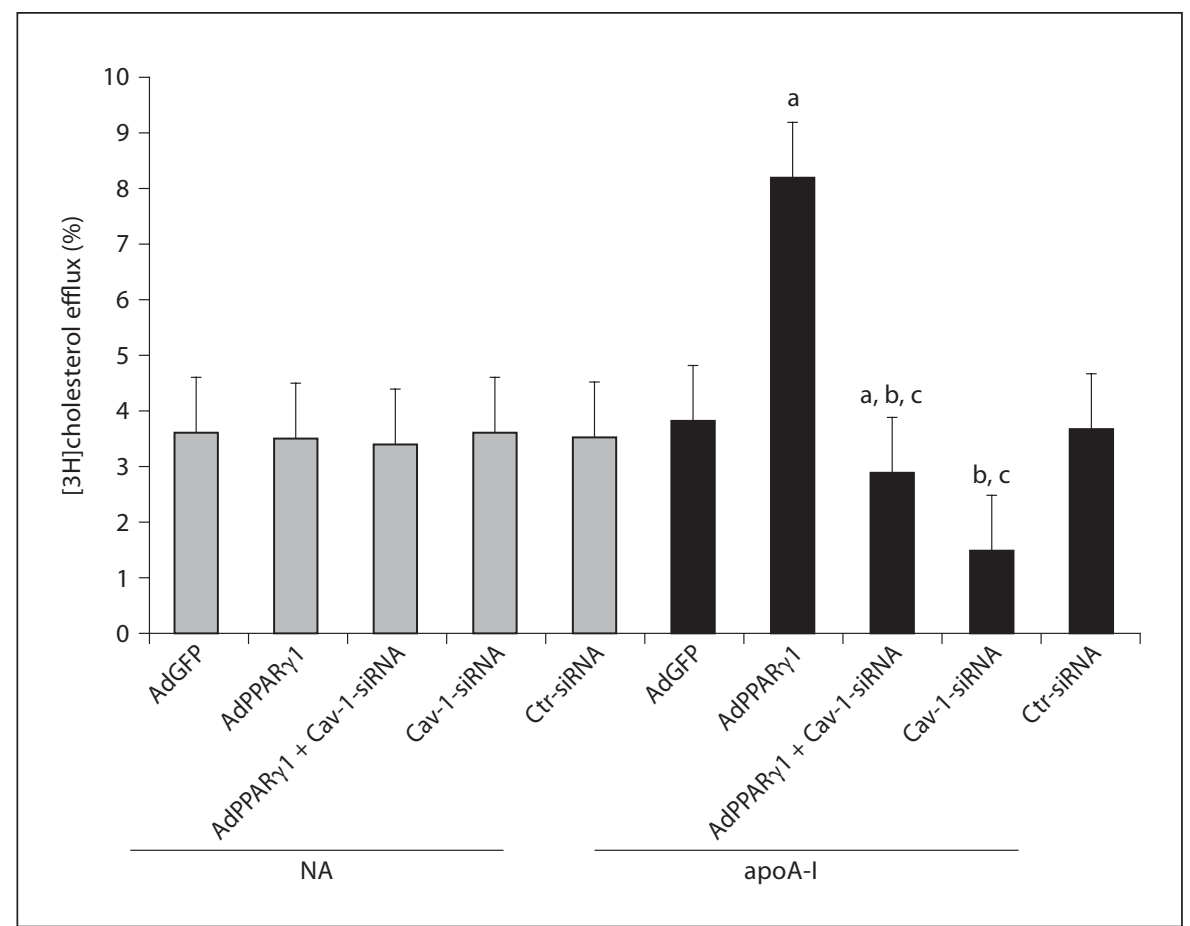

\section{Discussion}

Caveolae are 50- to 100-nm invaginations of the cell surface plasma membrane and are present in terminally differentiated cells. They are characterized by the presence of Cav-1, sphingolipids and cholesterol. Physiologically, the loss of caveolae results in impaired cholesterol homeostasis, insulin sensitivity, nitric oxide activity, calcium signaling and cardiac function. Although caveolinknockout mice are useful to delineate the importance of caveolae in a given response, other questions are difficult to assess because the loss of Cav- 1 and Cav- 3 abolishes both the caveolae organelle as well as the pathways regulated by protein-protein or protein-lipid interactions with the caveolins [17].

Cav-1, the major structural protein of caveolae, is present in several cell types known to play a role in the development of atherosclerosis [18]. Cav-1 is thought to play an important role in the regulation of cellular cholesterol homeostasis, a process that requires proper control to limit and prevent cholesterol accumulation and, eventually, atherosclerosis. Several lines of evidence now suggest that Cav-1 might play a proatherogenic role $[19,20]$. Loss of Cav-1 provides the molecular genetic evidence to support caveolar transcytosis of modified lipoproteins (from the blood to the sub-endothelial space) as a critical initiating step in atherosclerosis [21]. Frank et al. identified caveolae-type organelles as critical for atherosclerotic lesion progression in mice [1]. In endothelial cells, Cav-1 is upregulated on LDL exposure. Moreover, downregulation of Cav-1 is associated with reduced uptake of oxidized LDL by endothelial cells, because caveolae are proposed to play a major role in the transcytosis of native and modified LDL, with smooth muscle cell Cav-1 having the opposite role $[1,4,5,7,21]$. Monocyte-derived macrophages also play an important role in the development of atherosclerosis. They take up large amounts of modified lipids present in the subendothelial space of the arterial wall and form fatty streak lesions [22]. Evidence for caveolin expression in macrophages, however, has been scarce and conflicting. Macrophages were found not to express caveolin [23]. As well, immunoblot analyses have indicated Cav-1 expression in THP-1 cells but not J774 or RAW macrophages [24]. Contrary to these reports, Cav-1 mRNA was recently detected in J774 and RAW macrophages on RTPCR [25]. Cav-1 may positively or negatively influence the development of vascular disease, depending on the cell type and the metabolic pathways regulated by this protein. Therefore, whether vascular cells, especially those making up atherosclerotic plaque, even express caveolins or have caveolae-type organelles and whether 
caveolin-1 is pro-atherogenic or anti-atherogenic are currently debated.

In the current study, immunohistochemical analysis revealed Cav-1 expressed in the cellular membrane of RAW macrophages. Immunoblotting and RT-PCR results confirmed this phenomenon. We also found PPAR $\gamma$ expressed in RAW macrophages and in macrophage-derived foam cells of atherosclerotic lesions of apoE-deficient mice. Here, we provide direct evidence that PPAR $\gamma 1$ transfection attenuates the progression of established atheroma by reducing deposition of lipids and macrophages and increasing content of smooth muscle cells. Previous studies have suggested that Cav-1 expression is regulated by PPAR $\gamma$ in other cell types, such as human adenocarcinoma and hepatic cells $[9,10]$. Whether Cav-1 expression is regulated by PPAR $\gamma 1$ in RAW macrophages, even in aorta of apoE-deficient mice remains unclear. Our results clearly established that overexpression of PPAR $\gamma 1$ triggered the upregulation of Cav-1 genes in RAW macrophages. Our in vivo experimental data strongly suggested that this overexpression led to the upregulation of the Cav-1 gene in the aorta and the liver of apoE-deficient mice. Indeed, upregulated Cav-1 was chiefly distributed and expressed in endothelial cells, smooth muscle cells and macrophages, which make up the vessel wall and atheromatous plaques. Recently, Llaverias et al. [26] found that rosiglitazone, a PPAR $\gamma$ agonist, upregulated Cav-1 in THP-1 cells through a PPAR-dependent mechanism. Moreover, the upregulation of Cav1 in the liver 6 days after injection of AdPPAR $\gamma 1$ into $\mathrm{PPAR}^{-/-}$mice was verified by Affymatrix microarray chips [10].

At present, the mechanism regulating Cav-1 expression remains unclear. The functionality of the potential binding site was verified by a previous study with a double-stranded oligonucleotide containing the PPAR response element identified in the human Cav-1 promoter used as a probe [26]. Accordingly, we propose that the effect of PPAR $\gamma 1$ on Cav-1 expression may be mediated by transcription activation upon binding of PPAR $\gamma / \mathrm{RXR}$ heterodimers to the newly identified PPAR response element in the promoter of the murine Cav-1 gene, which may explain the phenomenon in part. However, further studies are needed to ascertain the precise mechanisms.

The data suggest that Cav-1 and $\mathrm{ABCA} 1$ are important proteins involved in cellular cholesterol efflux. Cholesterol efflux is a pathway for removing excessive cholesterol from cells to extracellular acceptors. It is the first step of reverse cholesterol transport and plays a key role in maintaining cell cholesterol homeostasis. Impaired cholesterol efflux leads to accumulation of intracellular cholesterol and development of atherosclerosis in animal models and in humans $[27,28]$. Regarding the increase, we found in high-density lipoprotein cholesterol, cholesterol efflux may be enhanced by AdPPAR $\gamma 1$ transfection. In this study, PPAR $\gamma 1$ overexpression enhanced cholesterol efflux in RAW264.7 cells and increased the mRNA level of cholesterol efflux-related molecules such as Cav$1, \mathrm{LXR} \alpha$ and ABCA1 in liver extracts from apoE-deficient mice. Previous study demonstrated that Cav-1 colocalizes with ABCA1 in the caveolae and in the cytoplasmic vesicles and with cellular cholesterol [29]. Indeed, these results imply another pathway influencing cholesterol efflux, possibly a PPAR $\gamma$-LXR $\alpha$-Cav-1 regulatory pathway, similar to that observed for other genes related to cholesterol efflux, such as ABCA1 and apoE. In this current study, we acutely down-regulated the expression of caveolin-1 in RAW264.7 cells to evaluate the direct role of this protein on cholesterol efflux. Here we provide evidence that the specific down-regulation of caveolin-1 impairs cholesterol efflux to apolipoprotein A-I. Moreover, we have demonstrated, for the first time, cholesterol efflux was enhanced in PPAR $\gamma$ treated Cav-1siRNA RAW264.7 cells, compared with Cav-1-siRNA RAW264.7 cells. In apoE-deficient mice, only 2 regulatory pathways seem to influence cholesterol efflux: PPAR $\gamma$-LXR $\alpha$-Cav- 1 and PPAR $\gamma$-LXR $\alpha$-ABCA1. This should be reevaluated using caveolin-specific silencing systems in apoE $\mathrm{E}^{-/-}$mice or caveolin-1/-/apoE $\mathrm{E}^{-/-}$mice. Therefore, further studies are needed to ascertain the precise mechanisms.

In conclusion, these data strongly support PPAR $\gamma 1$ gene transfer as increasing the expression of Cav-1 in RAW macrophages, especially in established atherosclerotic lesions of apoE-deficient mice. Moreover, PPAR $\gamma 1-$ induced Cav-1 upregulation actually confers protection against atherosclerosis. This observation may be due to some potential mechanisms: (1) the effects seem to be mediated by the binding of activated PPAR $\gamma 1$ to a new PPAR response element in an unidentified murine Cav-1 promoter; (2) enhancement of cholesterol efflux may be mediated by PPAR $\gamma$-LXR $\alpha$-Cav-1 or PPAR $\gamma$-LXR $\alpha$-ABCA 1 regulatory pathways in apoE-deficient mice; (3) with regard to enhancement of cholesterol efflux and altered lipoprotein status, PPAR $\gamma 1$-induced Cav-1 upregulation is likely anti-atherogenic in this model. However, we have no explanation of the net outcome on lipoprotein metabolism and lesion development of Cav-1 in apoE-deficient mice treated with PPAR $\gamma 1$, given the cellular data that: (1) caveolin-1 is a cholesterol-binding protein that 
can transport cholesterol from the endoplasmic reticulum to the plasma membrane, and (2) a major receptor for $\mathrm{HDL}$, scavenger receptor SR-B1, and a scavenger receptor for modified forms of LDL, CD36, can reside in and signal in caveolae-type microdomains [30]. Regardless of the above molecular mechanisms, other mechanisms may also participate in the increased Cav-1 expression and reduced atherosclerotic lesions after PPAR $\gamma 1$ treatment.

\section{Acknowledgments}

This study was supported by the National 973 Basic Research Program of China (No. 2006CB503803), the National Hi-tech Research and Development Program of China (No. 2006AA02A406) and grants from the National Natural Science Foundation of China (No. 30470701, 30570747 and 30670873) and the Provincial Science-Tech Development Program of Shandong (No. 2008GG30002021). Shu Qiang and Li Li are acknowledged for their technical assistance in lipid analysis and Movat's staining, respectively.

\section{References}

1 Frank PG, Woodman SE, Park DS, Lisanti MP: Caveolin, caveolae, and endothelial cell function. Arterioscler Thromb Vasc Biol 2003;23:1161-1168.

2 Hnasko R, Lisanti MP: The biology of caveolae: lessons from caveolin knockout mice and implications for human disease. Mol Interv 2003;3:445-464.

-3 Smart EJ, De Rose RA, Farber SA: Annexin 2 -caveolin 1 complex is a target of ezetimibe and regulates intestinal cholesterol transport. Proc Natl Acad Sci USA 2004;101: 3450-3455

-4 Frank PG, Cheung MW, Pavlides S, Llaverias G, Park DS, Lisanti MP: Caveolin-1 and regulation of cellular cholesterol homeostasis. Am J Physiol Heart Circ Physiol 2006;291: H677-H686.

5 Frank PG, Hassan GS, Rodriguez-Feo JA, Lisanti MP: Caveolae and caveolin-1: novel potential targets for the treatment of cardiovascular disease. Curr Pharm Des 2007;13: 1761-1769.

6 Lusis AJ: Atherosclerosis. Nature 2000;407: 233-241.

7 Frank PG, Lisanti MP: Caveolin-1 and caveolae in atherosclerosis: differential roles in fatty streak formation and neointimal hyperplasia. Curr Opin Lipidol 2004;15:523529.

$\checkmark 8$ Hassan GS, Jasmin JF, Schubert W, Frank PG, Lisanti MP: Caveolin-1 deficiency stimulates neointima formation during vascular injury. Biochemistry 2004;43:8312-8321.

$\checkmark 9$ Burgermeister E, Tencer L, Liscovitch M: Peroxisome proliferator-activated receptorgamma upregulates caveolin-1 and caveolin2 expression in human carcinoma cells. Oncogene 2003;22:3888-3900.

10 Yu S, Matsusue K, Kashireddy P, Cao WQ, Yeldandi V, Yeldandi AV, Rao MS, Gonzalez FJ, Reddy JK: Adipocyte-specific gene expression and adipogenic steatosis in the mouse liver due to peroxisome proliferatoractivated receptor gammal (PPARgammal) overexpression. J Biol Chem 2003;278:498505.
11 Staels B: PPARgamma and atherosclerosis. Curr Med Res Opin 2005;21(suppl 1):S13S20.

12 Hu Q, Zhang XJ, Zhang C, Zhao YX, He H, Liu CX, Feng JB, Jiang H, Yang FL, Zhang CX, Zhang Y: Peroxisome proliferator-activated receptor-gammal gene therapy attenuates atherosclerosis and stabilizes plaques in apolipoprotein E-deficient mice. Hum Gene Ther 2008;19:287-299.

13 He TC, Zhou S, da Costa LT, Yu J, Kinzler KW, Vogelstein B: A simplified system for generating recombinant adenoviruses. Proc Natl Acad Sci USA 1998;95:2509-2514.

14 Ghering AB, Davidson WS: Ceramide structural features required to stimulate ABCA1mediated cholesterol efflux to apolipoprotein A-I. J Lipid Res 2006;47:2781-2788.

15 Majdalawieh A, Zhang L, Fuki IV, Rader DJ, Ro HS: Adipocyte enhancer-binding protein 1 is a potential novel atherogenic factor involved in macrophage cholesterol homeostasis and inflammation. Proc Natl Acad Sci USA 2006;103:2346-2351.

16 Li AC, Glass CK: PPAR- and LXR-dependent pathways controlling lipid metabolism and the development of atherosclerosis. J Lipid Res 2004;45:2161-2173.

$\$ 17$ Le Lay S, Kurzchalia TV: Getting rid of caveolins: phenotypes of caveolin-deficient animals. Biochim Biophys Acta 2005; 1746 : 322-333.

18 Williams TM, Lisanti MP: The caveolin genes: from cell biology to medicine. Ann Med 2004;36:84-595.

19 Lin WW, Lin YC, Chang TY, Tsai SH, Ho HC, Chen YT, Yang VC: Caveolin-1 expression is associated with plaque formation in hypercholesterolemic rabbits. J Histochem Cytochem 2006;54:897-904.

20 Sedding DG, Braun-Dullaeus RC: Caveolin1: dual role for proliferation of vascular smooth muscle cells. Trends Cardiovasc Med 2006;16:50-55.

21 Frank PG, Lee H, Park DS, Tandon NN, Scherer PE, Lisanti MP: Genetic ablation of caveolin-1 confers protection against atherosclerosis. Arterioscler Thromb Vasc Biol 2004;24:98-105.
22 Gargalovic P, Dory L: Caveolins and macrophage lipid metabolism. J Lipid Res 2003;44: 11-21.

23 Fielding CJ, Fielding PE: Intracellular cholesterol transport. J Lipid Res 1997;38:15031521.

24 Matveev S, van der Westhuyzen DR, Smart EJ: Co-expression of scavenger receptor-BI and caveolin-1 is associated with enhanced selective cholesteryl ester uptake in THP-1 macrophages. J Lipid Res 1999;40:16471654.

25 Lei MG, Morrison DC: Differential expression of caveolin-1 in lipopolysaccharide-activated murine macrophages. Infect Immun 2000;68:5084-5089.

-26 Llaverias G, Vázquez-Carrera M, Sánchez RM, Noé V, Ciudad CJ, Laguna JC, Alegret M: Rosiglitazone upregulates caveolin-1 expression in THP-1 cells through a PPAR-dependent mechanism. J Lipid Res 2004;45: 2015-2024.

27 Dhaliwal BS, Steinbrecher UP: Cholesterol delivered to macrophages by oxidized low density lipoprotein is sequestered in lysosomes and fails to efflux normally. J Lipid Res 2000;41:1658-1665.

-28 van Dam MJ, de Groot E, Clee SM, Hovingh GK, Roelants R, Brooks-Wilson A, Zwinderman AH, Smit AJ, Smelt AH, Groen AK, Hayden MR, Kastelein JJ: Association between increased arterial-wall thickness and impairment in ABCA1-driven cholesterol efflux: an observational study. Lancet 2002; 359:37-42.

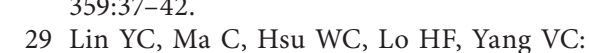
Molecular interaction between caveolin-1 and ABCA1 on high-density lipoproteinmediated cholesterol efflux in aortic endothelial cells. Cardiovasc Res 2007;75:575-

583.
30 Sessa WC: Atheroprotection in the absence of 'caves': is it the fat, the vessels, or both? Arterioscler Thromb Vasc Biol 2004;24: 4-6. 